\title{
Measuring Flow-Induced Crystallization Kinetics of Polyethylene after Processing
}

\author{
Kenneth L. Kearns, ${ }^{* 1}$ Justin Scherzer, ${ }^{1}$ Marius Chyasnavichyus, ${ }^{1}$ Daria Monaenkova, ${ }^{1}$ \\ Jonathan Moore, ${ }^{2}$ Robert L. Sammler, ${ }^{2}$ Tom Fielitz, ${ }^{1}$ David A. Nicholson, ${ }^{3}$ Marat Andreev, ${ }^{3}$ \\ Gregory C. Rutledge $e^{3}$ \\ ${ }^{1}$ The Dow Chemical Company, Core R\&D, Analytical Science, Midland, MI 48667 \\ 2 The Dow Chemical Company, Core R\&D, Formulation, Automation and Material Science, \\ Midland, MI 48667
}

${ }^{3}$ Department of Chemical Engineering, Massachusetts Institute of Technology, Cambridge, MA 02139

Molecular weight using size-exclusion chromatography (SEC). SEC was performed using a Polymer Laboratories Model 220 high temperature liquid chromatograph in trichlorobenzene, TCB, with 200 ppm 2,5-di-tert-butyl-4-methylphenol (BHT, Sigma-Aldrich) at $150{ }^{\circ} \mathrm{C}$. Four 10$\mu \mathrm{m}$ mixed-porosity analytical columns (Agilent) were used as the separation media. Calibration was carried out using 21 narrow polystyrene standards. This calibration was converted to polyethylene-equivalent molecular weight and referenced against linear homopolymer (NIST SRM 1475). $200 \mu \mathrm{L}$ of a $2.0 \mathrm{mg} / \mathrm{mL}$ polymer solution was injected using a flow rate of $1.0 \mathrm{~mL} / \mathrm{min}$. A fixed-wavelength infrared detector (Polymer Char IR4) was coupled in series to the internal 
refractometer of the chromatograph for simultaneous measurement. Data processing was performed using GPC One Software from Polymer Char.

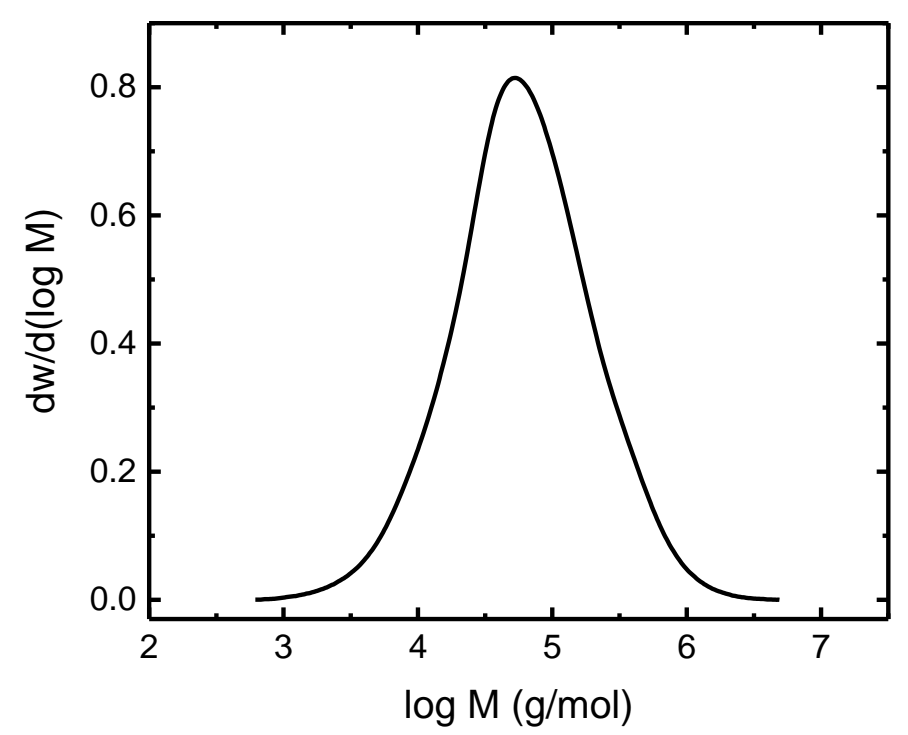

Figure S1. Molecular weight distribution of LLDPE.

Crystallization Elution Fractionation (CEF). CEF was used to determine the chemical composition distribution and has been described previously by Monrabal, et al. ${ }^{1}$ The instrument was equipped with both an IR-5 (Polymer Char, Spain) and a Model 2040 two-angle light scattering detector (Agilent Technologies). A $10 \mu \mathrm{m}$ guard column of 50 x $4.6 \mathrm{~mm}$ (Agilent Technologies) was installed before the IR-5 detector in the detector oven. Ortho-dichlorobenzene, ODCB, (99\% anhydrous grade from Sigma-Aldrich) with 1200 ppm BHT were used. The solution was sparged with dry nitrogen prior to use. Sample preparation was done using an autosampler at $4 \mathrm{mg} / \mathrm{ml}$ under shaking at $160^{\circ} \mathrm{C}$ for 2 hours. The injection volume was $300 \mu \mathrm{l}$. The temperature profile of the $\mathrm{CEF}$ was the following: crystallization at $3^{\circ} \mathrm{C} / \mathrm{min}$ from $110^{\circ} \mathrm{C}$ to $30^{\circ} \mathrm{C}$, with thermal equilibrium at $30^{\circ} \mathrm{C}$ for 5 minutes elution at $3^{\circ} \mathrm{C} / \mathrm{min}$ from $30^{\circ} \mathrm{C}$ to $140^{\circ} \mathrm{C}$. The flow rate during crystallization was $0.052 \mathrm{ml} / \mathrm{min}$. The flow rate during elution was $0.50 \mathrm{ml} / \mathrm{min}$. 


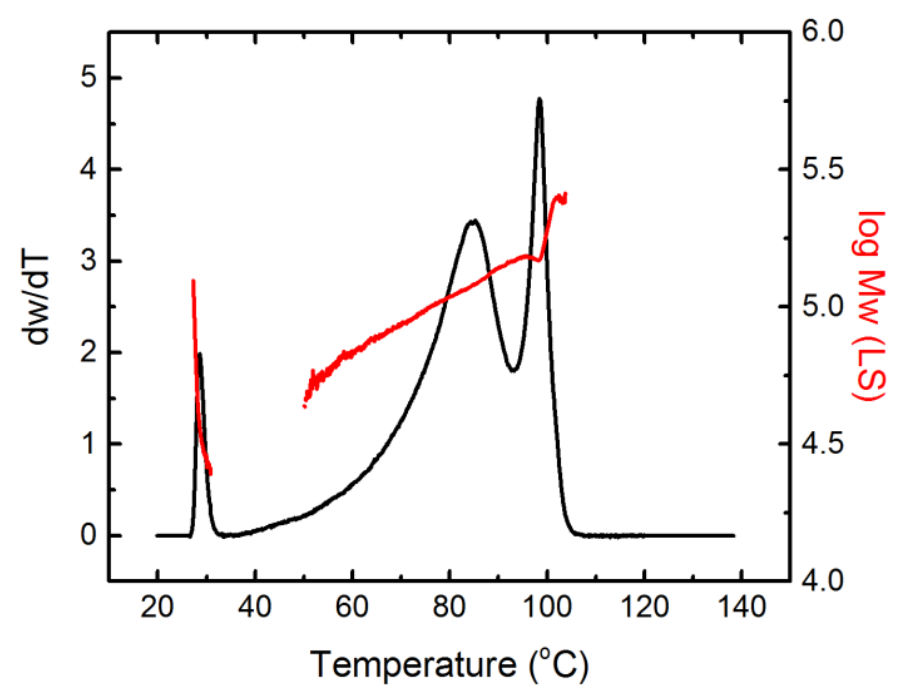

Figure S2. Crystallization elution fractionation (CEF) data for LLDPE. dw/dT is shown as the black line (left $\mathrm{y}$-axis) and the $\log$ of the $\mathrm{M}_{\mathrm{w}}$ signal from light scattering is the red line (right $\mathrm{y}$ axis).

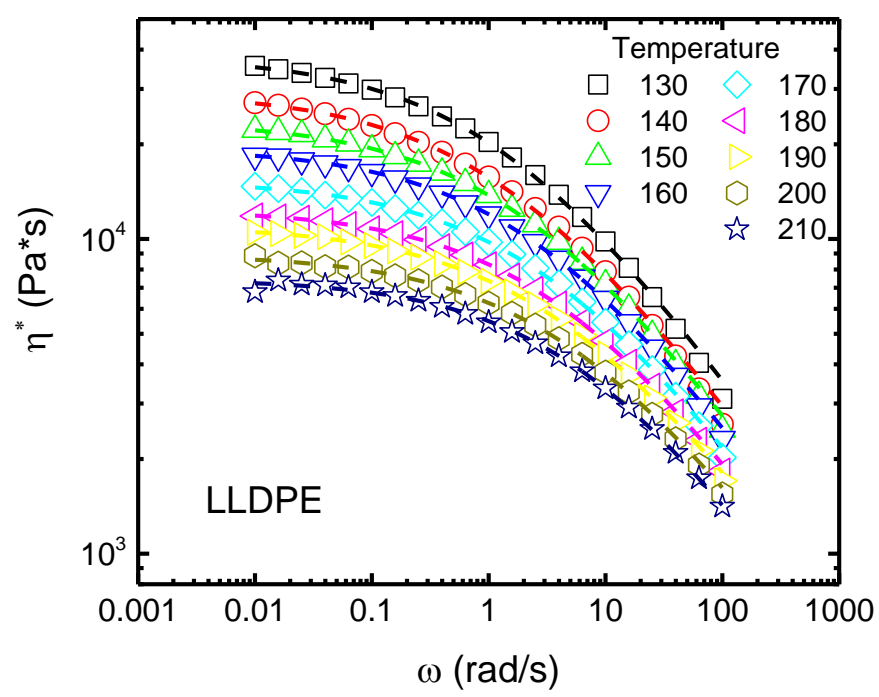

Figure S3. Frequency dependent complex viscosity for LLDPE from 130 to $210{ }^{\circ} \mathrm{C}$ (symbols). Fits to the data using the Cross model ${ }^{2}$ are shown as the dashed lines. 


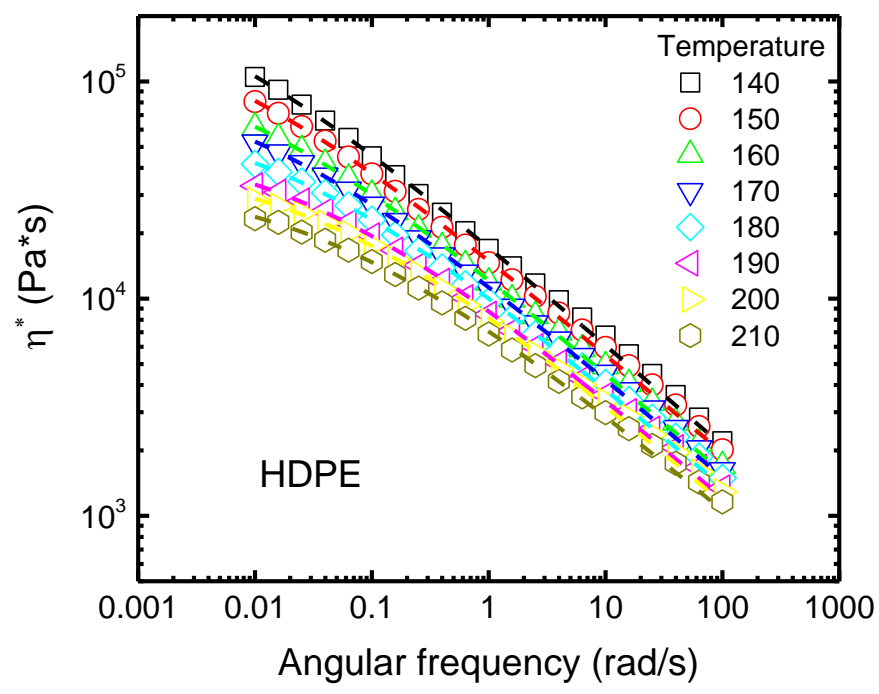

Figure S4. Frequency dependent complex viscosity for HDPE from 140 to $210{ }^{\circ} \mathrm{C}$ (symbols). Fits to the data using the Cross model ${ }^{2}$ are shown as the dashed lines.

Table S1. Fitting parameters to the Cross model for LLDPE at each temperature studied.

\begin{tabular}{c|ccc} 
Temperature $\left({ }^{\circ} \mathbf{C}\right)$ & $\boldsymbol{\eta}_{\mathbf{0}}$ & $\boldsymbol{\tau}$ & $\boldsymbol{\beta}$ \\
\hline 130 & 36420 & 0.619 & 0.436 \\
140 & 28020 & 0.590 & 0.451 \\
150 & 22950 & 0.442 & 0.453 \\
160 & 19040 & 0.355 & 0.456 \\
170 & 15060 & 0.300 & 0.462 \\
180 & 12250 & 0.241 & 0.4613 \\
190 & 10850 & 0.230 & 0.474 \\
200 & 8755 & 0.171 & 0.4648 \\
210 & 7587 & 0.160 & 0.4755
\end{tabular}

Table S2. Fitting parameters to the Cross model for HDPE at each temperature studied. 


\begin{tabular}{c|ccc} 
Temperature $\left({ }^{\circ} \mathbf{C}\right)$ & $\boldsymbol{\eta}_{\mathbf{0}}$ & $\boldsymbol{\tau}$ & $\boldsymbol{\beta}$ \\
\hline 140 & 220000 & 1877.9 & 0.561 \\
150 & 76000 & 750 & 0.567 \\
160 & 41000 & 490 & 0.5701 \\
170 & 23000 & 290 & 0.5727 \\
180 & 12000 & 146 & 0.5739 \\
190 & 7000 & 85 & 0.5743 \\
200 & 4900 & 55 & 0.5747 \\
210 & 3300 & 44 & 0.5794
\end{tabular}

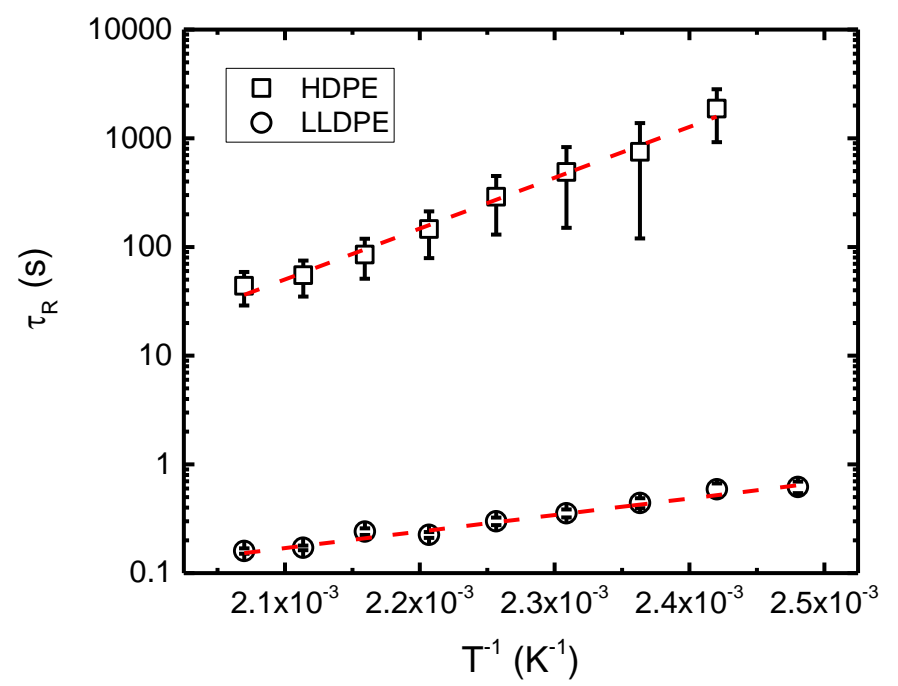

Figure S5. Arrhenius plot of the relaxation times for HDPE (open squares) and LLDPE (open circles) with fits (dashed red line).

$$
\ln \left(\tau_{R}\right)=\ln (Z)+\frac{E_{a}}{R} * T^{-1}
$$

\section{Equation 1}


Table 3. Parameters from Arrhenius fits to the relaxation data in Figure S5.

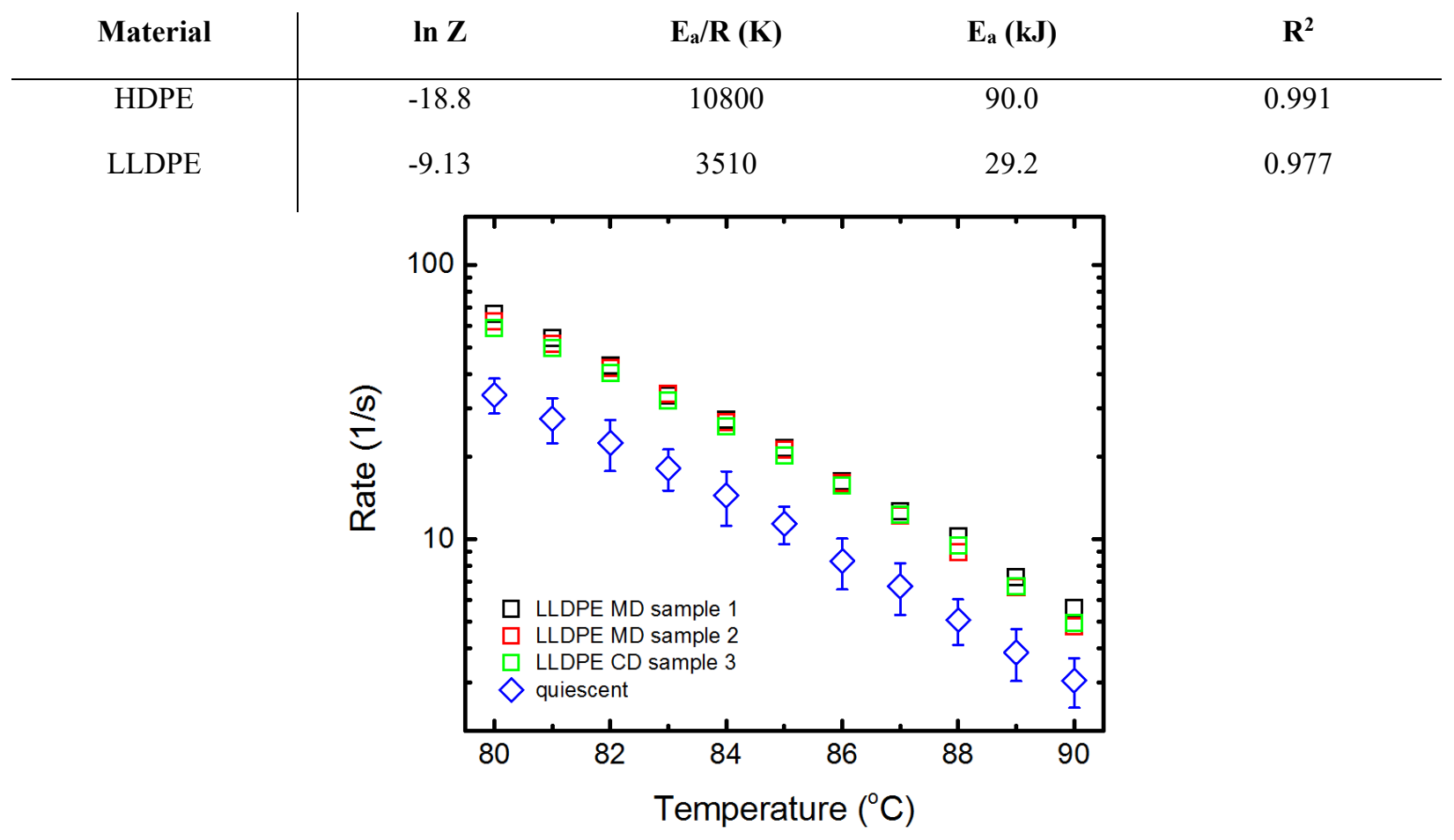

Figure S6. Reproducibility of flow-induced crystallization measurement for a blown film of LLDPE (open squares). Film cut in cross-direction (CD - perpendicular to the machine direction) and machine-direction (MD) are shown along with the quiescent data. Error bars for the quiescent data are one standard deviation of four measurements on separate samples and FSC sensors. 


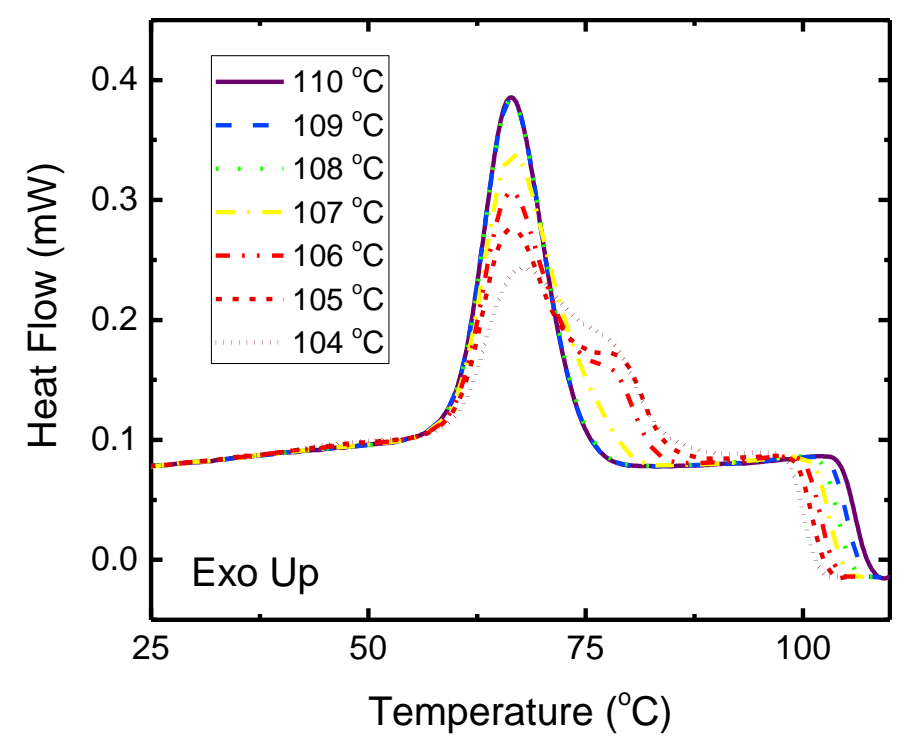

Figure S7. Cooling curves for LLDPE after cooling from the temperatures given in the legend at a cooling rate of $1000{ }^{\circ} \mathrm{C} / \mathrm{s}$. The temperature was held isothermally for $0.2 \mathrm{~s}$ prior to cooling to $95{ }^{\circ} \mathrm{C}$.

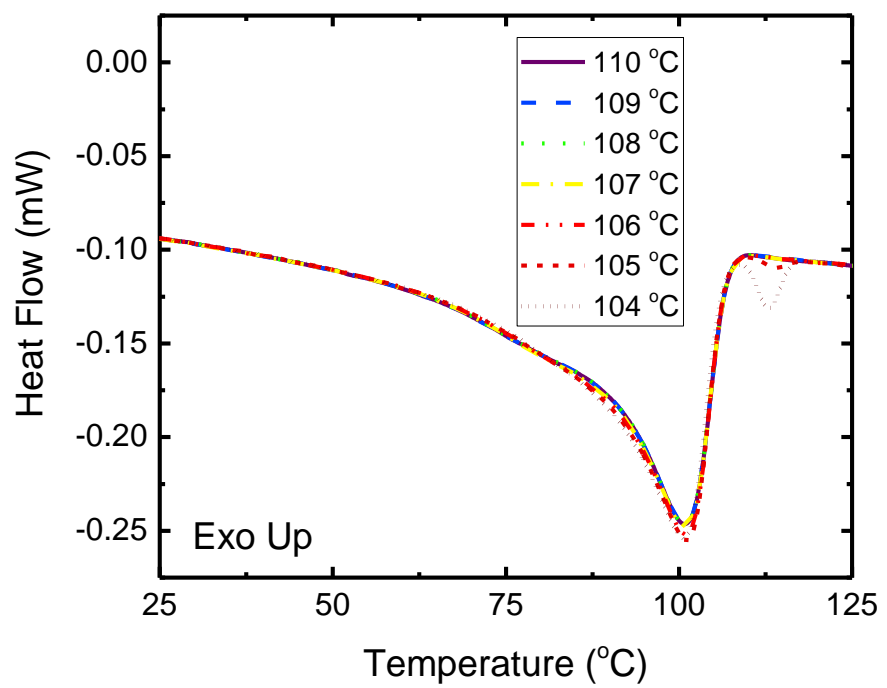

Figure S8. Heating curves for LLDPE after cooling from the temperatures given in the legend. The heating rate was $1000{ }^{\circ} \mathrm{C} / \mathrm{s}$. Prior to heating, the sample was held at $-95^{\circ} \mathrm{C}$ for $0.2 \mathrm{~s}$. 


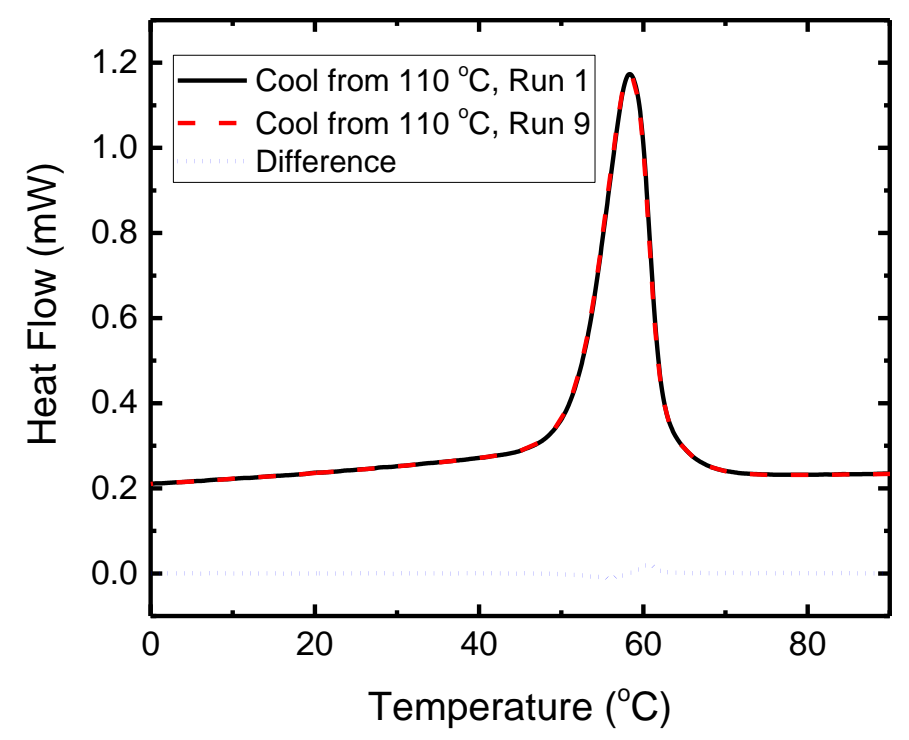

Figure S9. Cooling curves collected at $1000^{\circ} \mathrm{C} / \mathrm{s}$ after heating to a $T_{m, \text { upper }}$ of $110^{\circ} \mathrm{C}$. The cooling curves for the first (solid, black) and ninth (dashed, red) thermal cycling of the same sample are shown. The difference between these two runs is shown as the blue dotted line.

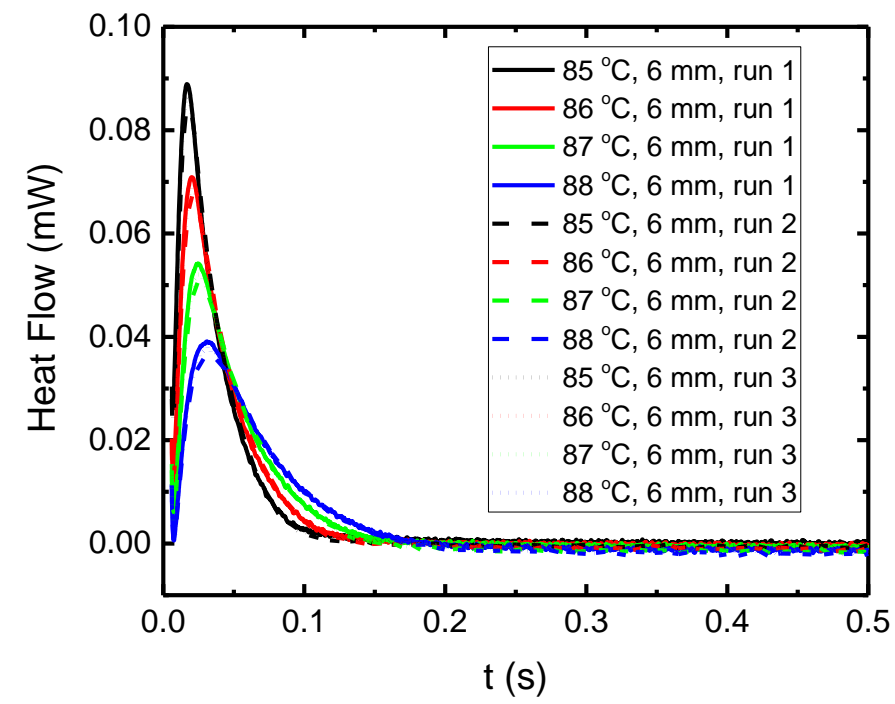

Figure S10. Time-dependent heat flow during isothermal crystallization for sample microtomed $6 \mathrm{~mm}$ from the center of the sheared plaque. Data is shown for isothermal temperatures of 85 (black), 86 (red), 87 (green) and $88^{\circ} \mathrm{C}$ (blue). Three consecutive runs are shown as the solid, dashed and dotted lines for the first, second and third runs, respectively. $\mathrm{T}_{\mathrm{m} \text {,upper }}$ was $109^{\circ} \mathrm{C}$ in all cases. 


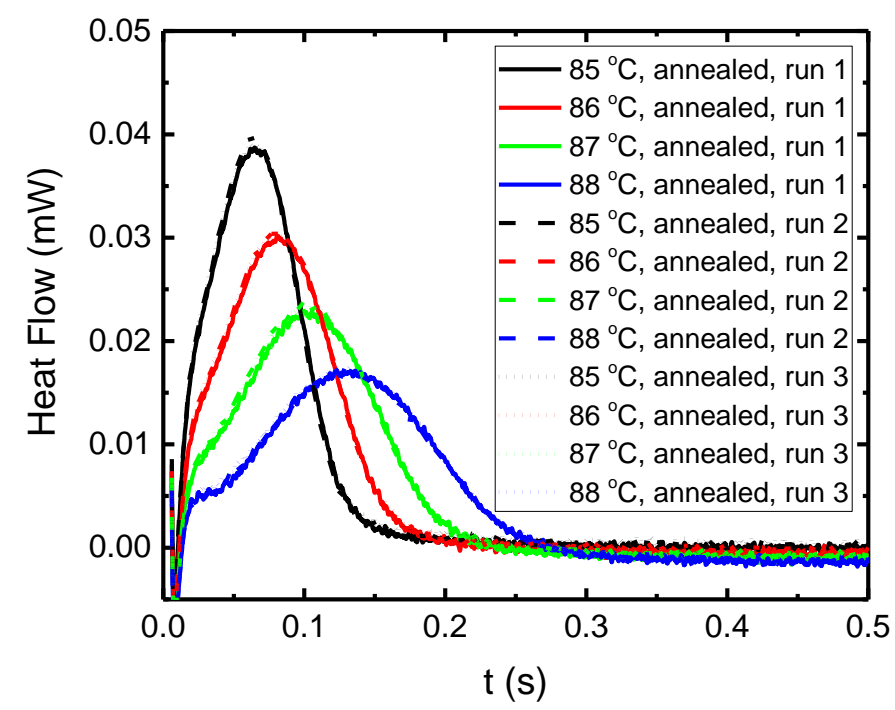

Figure S11. Time-dependent heat flow during isothermal crystallization for sample microtomed $6 \mathrm{~mm}$ from the center of the sheared plaque and annealed at $185^{\circ} \mathrm{C}$ for 5 seconds. Data is shown for isothermal temperatures of 85 (black), 86 (red), 87 (green) and $88^{\circ} \mathrm{C}$ (blue). Three consecutive runs are shown as the solid, dashed and dotted lines for the first, second and third runs,

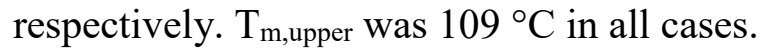
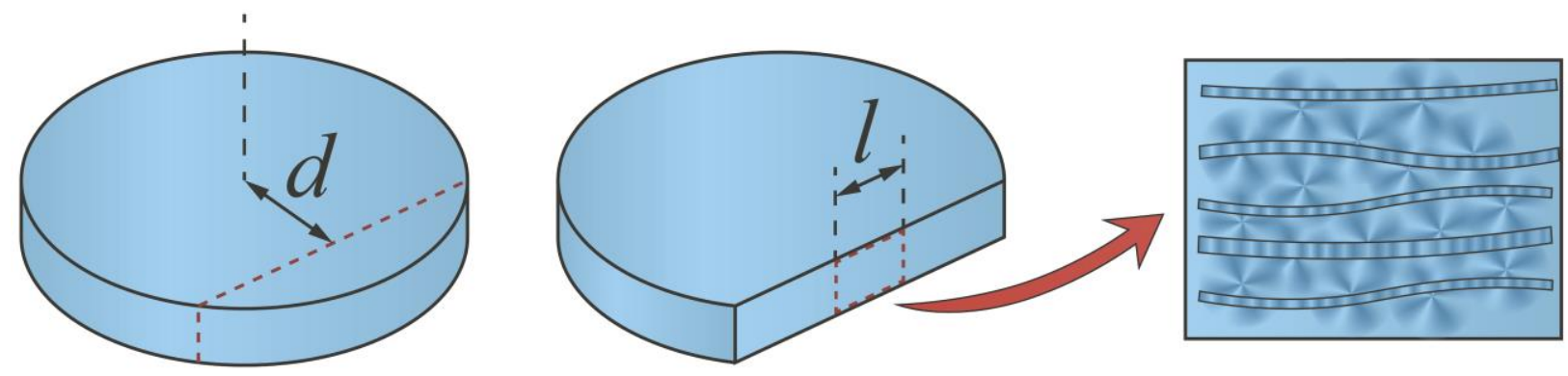

Figure S12. Schematic of the cryo-microtomy sectioning protocol used to prepare samples for FSC. $d$ is the distance from the center of the disc and $l$ is the lateral size of the microtomed section. 


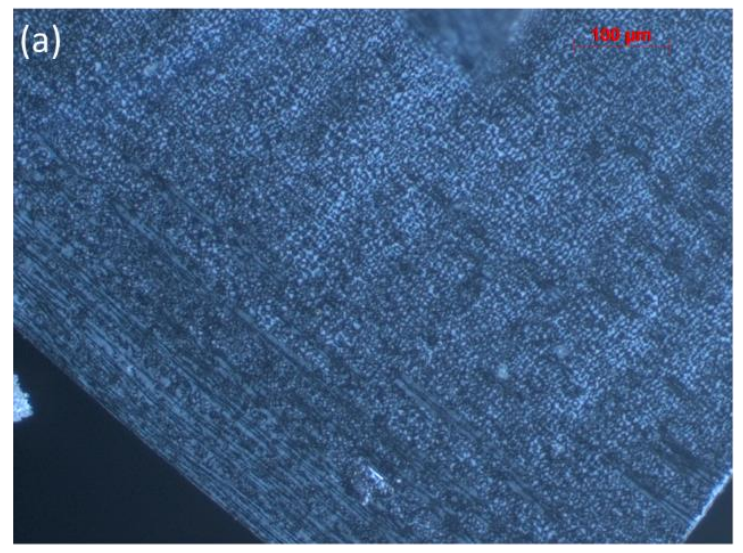

Figure S13. Optical microscopy through crossed polarizers of a microtomed section of LLDPE from the sheared plaque at a radial position of $6 \mathrm{~mm}$.

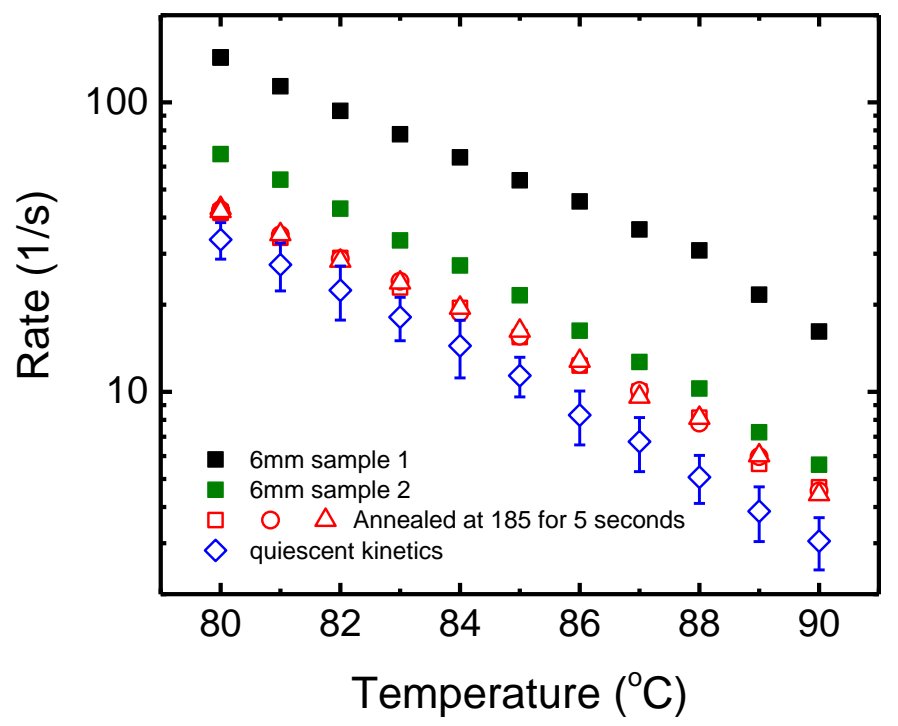

Figure S14. Crystallization rate data for two different samples of LLDPE taken from $6 \mathrm{~mm}$ from the origin of the sheared plaque (filled black and green symbols). Rate data after annealing sample 1 (black) is shown as the open red symbols. Quiescent data (open diamonds) are shown as a comparison. 


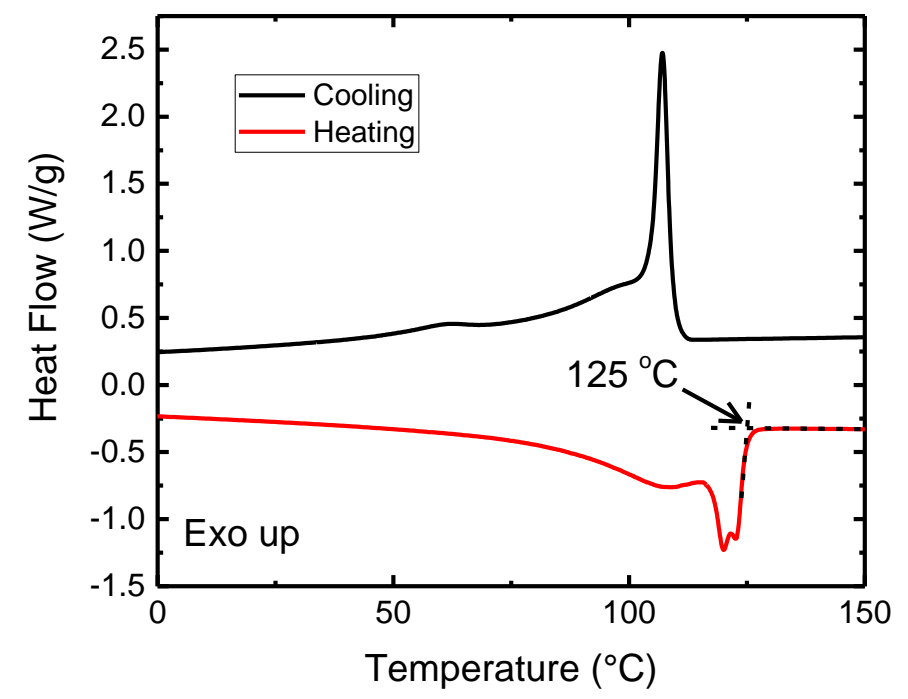

Figure S15. Conventional DSC data collected at $10^{\circ} \mathrm{C} / \mathrm{min}$ for the LLDPE used in this study. The cooling curve was collected prior to heating. The completion of melting is shown as the intersection of the dashed lines.

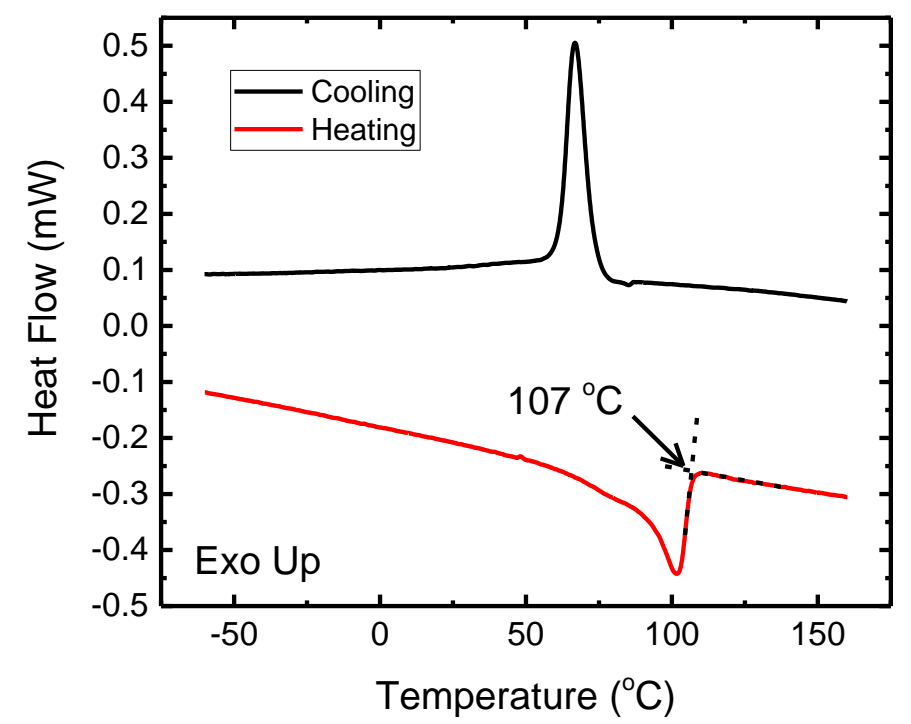

Figure S16. Fast-scanning calorimetry data collected at $1000{ }^{\circ} \mathrm{C} / \mathrm{s}$ for the LLDPE used in this study. The cooling curve was collected prior to heating. The completion of melting is shown as the intersection of the dashed lines.

\section{REFERENCES}


1. Monrabal, B.; Romero, L.; Mayo, N.; Sancho-Tello, J. Advances in Crystallization Elution Fractionation. Macromol. Symp. 2009, 282, 14-24.

2. Cross, M. M. Rheology of non-Newtonian fluids: A new flow equation for pseudoplastic systems. J. Colloid Sci. 1965, 20 (5), 417-437. 